\title{
Study on Seasonal Fluctuation of Physicochemical Properties of Water and Fish Diversity Towards Future Management of a Natural Water Bodies Rajar Beel Wetland, North 24 Parganas, West Bengal, India
}

\author{
Triparna Chakraborty and Nimai Chandra Saha*
}

\author{
Department of Zoology, Fisheries and Ecotoxicology Research Laboratory (Vice Chancellor's \\ Research Group), The University of Burdwan, West Bengal, India \\ *Corresponding author
}

Keywords

Health status,

Seasonal

fluctuation, Physicochemical properties, Diversity indices, Freshwater, Sustainability

Article Info

Accepted: 18 March 2021 Available Online: 10 April 2021
The present study was made to find out the health status of a wetland Rajar Beel, North 24 Parganas, West Bengal, India in relation to physicochemical properties of water. This wetland is rich in aquatic biodiversity. The study focused on the seasonal fluctuation of physicochemical parameters of water and diversity of fish fauna during pre-monsoon, monsoon and post-monsoon during March 2019 to February 2020. Water samples and fish specimens were collected from three different sites of the beel every month to evaluate the correlation between physicochemical properties of water and the indices of fish diversity. A significant seasonal fluctuation in fish diversity in relation to physicochemical parameters (temperature $23-30^{\circ} \mathrm{C}$, turbidity $18.5-26.5 \mathrm{~cm}, \mathrm{pH}$ 7.1-8.4, $\mathrm{CO}_{2}$ 0-40 mg/l, DO 4-7 mg/l, TA $155-218 \mathrm{mg} / \mathrm{l}$, TH 105-186 mg/l, phosphate $0.15-0.41 \mathrm{mg} / \mathrm{l}$ and nitrate $0.03-0.15 \mathrm{mg} / \mathrm{l}$ of water) was recorded during the study period. In respect of fish faunal diversity, a total of 37 species belonging to 9 orders and 22 families were identified. Maximum representatives belong to order Cypriniformes having 7 species with $43.91 \%$ catch composition, whereas Perciformes with 15 species with $28.93 \%$ catch composition. The beel was heavily infested with aquatic vegetation creating complex environments for the growth of different faunal populations. The present study indicates that the beel is moderately productive and suitable for commercial aquaculture. This study will be helpful in the determination of the health status of the beel. The effect of seasonal variations on the assemblage of fish composition is found to be important and it should be considered into account when developing initiatives will be taken in the future to support the productivity and biodiversity of the wetland. 


\section{Introduction}

Wetlands are considered biologically the most productive ecosystem and are considered as the kidney of the earth (Ramachandran et al., 2006). This habitat is rich in biodiversity (Groombridge and Jenkins, 1998). Wetlands are the intermediate zone between land and water which are permanently or temporarily filled up with static or flowing, fresh, or saline water (Ramsar, 2012).

Freshwater wetlands are important feeding, breeding and drinking areas for various vertebrate and invertebrate species and home to some of the most productive and unique ecosystem. Fish species are a significant aspect of the aquatic environments and occupy a remarkable position from a socioeconomic viewpoint (Bera et al., 2015). Variation in water quality characteristics and their relationship with indices of biodiversity also are important factors for assessing the biodiversity of fish in floodplain wetlands (Mondal and Kaviraj, 2010). Productivity of wetlands are improved by constant surveillance of water quality parameters which are needed to be controlled periodically, independently, or collectively to preserve the optimal aquatic environments (Mondal and Kaviraj, 2008). Various researches (Das and Chand, 2003; Madhuri and Gurav, 2008; Jawale and Patil, 2009; Abujam et al., 2011; Sharma et al., 2016) were carried out to measure and evaluate the abiotic parameters in relation to the productivity status of the lentic ecosystem.

West Bengal, an eastern Indian state, has several floodplain lakes encompassing a segment of 42,000 ha, accounting for around $22 \%$ of the entire state's freshwater habitat (Bhaumik et al., 2003). Approx 8861 ha of water resources are found in North 24 Parganas district (Annual report 2004-2005, Department of Fisheries, Government of West
Bengal). Rajar beel is one of the important wetland of North 24 parganas. Various researchers (Sarkar and Benerjee, 2000; Keshre and Mudgal, 2010; Singh, 2011; Kumar, 2012; Naik et al., 2013; Basavaraja et al., 2014) have reported about the physicochemical status and ichthyofauna diversity of various wetlands. But Rajar Beel's across the board information on fish biodiversity in regarding the water quality is insufficient.

In the present study, the main focus is to evaluate the limnological parameters of water and its connection with the fish biodiversity indices in several sites of Rajar Beel to assess its health status during pre-monsoon, monsoon and post-monsoon from March 2019 to February 2020.

\section{Materials and Methods}

\section{Study Area}

Rajar beel also known as Prakito Jolashay (Latitude $\quad 22^{\circ} 42^{\prime} 54.1 " \mathrm{~N}$; $\quad$ Longitude $88^{\circ} 24^{\prime} 30.7^{\prime \prime E}$ ) (Figure 1) falls under North 24 Parganas districts of West Bengal, India, at an altitude of 6 meters above sea level. Rajar Beel wetland spreads over an area of 34 hectares. The area is mainly rain-fed. The fisherman utilizes this wetland for fish capture. Sewage from the municipality, domestic disposal directly mixes up in this wetland.

\section{Sampling Methods}

The study was conducted on monthly basis from March 2019 to February 2020 for the analysis of physicochemical parameters and the relationship of those parameters with fish diversity. A total of three representative sampling sites (Site I = Sadarhat Ghat, Site II = Taltala Ghat, Site III = Parthpur Ghat) were selected. The most variable and responsive 
variables of water quality, like water temperature, $\mathrm{pH}$, Turbidity, Dissolved Oxygen (DO) and Free $\mathrm{CO}_{2}$ were measured in-situ, while rest parameters (Nitrate, Total Hardness as $\mathrm{CaCO}_{3}$, Total Alkalinity as $\mathrm{CaCO}_{3}$ and Phosphate) were analyzed in the laboratory.

The collection of water samples was done between 5 am to $8 \mathrm{am}$. Sample preservation and evaluation of different water quality index were performed according to standard procedures stated in APHA, (2006). The outcomes of the physicochemical study of the water sample were matched with the Indian Standards Bureau (BIS, 1993) and the Central Pollution Control Board (CPCB).

The fishes were captured at three stations with local nets and were confirmed by Talwar and Jingham method. The diversity and evenness indices were calculated by the references of Shannon \& Wiener (1949). Pearson linear correlation was played to see the connection between various physicochemical parameters.

To evaluate the diversity indices, random fish samples were extracted from five nettings across each site were collected to produce a $1 \mathrm{~kg}$ sample of small wild fish for every site per month. From these data Shannon-Weiner species diversity index $(\bar{H})$, Evenness index [J], Index of Dominance [ID] and Relative Abundance (RA) were calculated by below mentioned equations :

S.W. Species Diversity index

$\bar{H}=-\sum_{\mathrm{i}=1}^{Q}\left(\frac{\mathrm{Ni}}{\mathrm{N}}\right) \log _{2}\left(\frac{\mathrm{Ni}}{\mathrm{N}}\right)$

Where $\mathrm{S}$ is the total number of species; $\mathrm{N}$ is the total number of the individual; $\mathrm{N} i$ is the number of specimens in each species.

Evenness Index $(\mathrm{J})=\bar{H} / \log _{2} S$

Where $\bar{H}$ is the S.W. Species Diversity Index; $\mathrm{S}$ is the total number of species.
Index of Dominance (ID) $=\Sigma\left(\frac{\mathrm{Ni}}{N}\right)^{2}$

Where $\mathrm{N}$ is the total number of the individual; $\mathrm{N} i$ is the number of specimens in each species.

Relative Abundance $(\%)=\mathrm{N}^{\text {th }} / \mathrm{N}$ X 100

Where, $\mathrm{N}^{\text {th }}=$ Total Number of individual species; $\mathrm{N}=$ Total Number of species population.

\section{Results and Discussion}

In Rajar beel water temperature showed a positive correlation with turbidity and $\mathrm{CO}_{2}$ whereas negative correlation with $\mathrm{pH}$, dissolved oxygen, total alkalinity, nitrate, and phosphate (Table 1 and Figure 3). Ziauddin et.al., (2013) reported that minimum and maximum temperature in beels of West Bengal varied from 17.5 to $35.0{ }^{\circ} \mathrm{C}$, which conforms with the present study.

The higher $\mathrm{pH}$ was recorded in post-monsoon due to the low level of water, higher nutrient content, during the monsoon. In Rajar beel, $\mathrm{pH}$ showed a positive correlation with $\mathrm{DO}, \mathrm{TH}$ and TA while showed a negative correlation (Table 1 and Figure 3) with turbidity, water temperature and $\mathrm{CO}_{2}$. The results of the present investigation are comparable with $\mathrm{S}$ Debnath \& A Panigrahi (2013).

A water body's transparency usually suggests its effectiveness. Throughout the monsoon month, it was found to be a maximum that may be attributed to the entry of rainwater from the surrounding area. Throughout premonsoon and post-monsoon it was generally low which shows similarities to earlier work (Mamta Joshi et. al., 2019). In Rajar beel, turbidity showed a positive correlation (Table 1 and Figure 3) with dissolved oxygen, nitrate and phosphate whereas it showed a negative correlation with $\mathrm{pH}, \mathrm{CO}_{2}$ and total hardness. Dissolved oxygen attributes are inversely 
related to the temperature cycle, differing from post-monsoon upside to pre-monsoon lowest point, similar observations also reported by A. Bhatnagar and G. Singh (2010) in Hariyana. In the present investigation, dissolved oxygen of the wetlands shows a negative correlation (Table 1 and Figure 3) with temperature and $\mathrm{CO}_{2}$ but showed a positive correlation with $\mathrm{pH}$ and nitrate.

In pre-monsoon the amount of Free $\mathrm{CO} 2$ remain high due to the rapid decomposition of organic matter and high water temperature (Hasan et al., 2011; Shinde et al., 2011). Lacking free carbon dioxide in other seasons could be due to its utilization by phytoplankton and other aquatic plants via photosynthesis and retain by calcium in form of the calcium bicarbonate. The free carbon dioxide shows a significant positive correlation with temp while negative with rest of the parameters.

The maximum total hardness was obtained in post-monsoon due to some construction activity. Nasim Ahmad Ansari (2017), also reported similar observations in Surajpur wetland. In Rajar beel, TH showed a negative correlation with water temp, turbidity, $\mathrm{CO}_{2}$ and phosphate but showed a positive correlation with $\mathrm{pH}$, nitrate and $\mathrm{DO}$.

In the present study the value of total alkalinity shows close similarity with the other researchers data (Arya et al., 2011; Mishra et al., 2014). In Rajar beel, TA showed a positive correlation with $\mathrm{pH}, \mathrm{DO}$, nitrate and phosphate but showed a negative correlation with water temperature, turbidity and $\mathrm{CO}_{2}$. The amount of nitrate in all three sites of this beel were found very low. During the monsoon and post-monsoon period however the level of nitrate was found bit high due to the surface runoff and some microbial activity. In winter, the activities of these microbes go down (Kaur et al., 1996) resulting in a higher value of nitrate. In Rajar Beel, nitrate showed a positive correlation with phosphate, $\mathrm{pH}$ and DO but negative correlation with water temp and $\mathrm{CO}_{2}$.

Phosphorus in water commonly exists as phosphate. The phosphate concentration in water above $0.5 \mathrm{mg} \mathrm{l}^{-1}$ indicates pollution (Jain et al.,1996) in water. Maximum phosphate was observed in Rajar beel during the monsoon and minimum during the premonsoon. In Rajar beel, phosphate showed a negative correlation (Table 1 and Figure 3) with water temperature, $\mathrm{TH}$ and $\mathrm{CO}_{2}$ while the positive correlation with $\mathrm{pH}, \mathrm{DO}$ and nitrate was observed. The concentration of phosphate which was moderate throughout the year indicates that this beel is mesotrophic.

The mesotrophic floodplain ecosystem has acceptable phosphorus levels and seems to be ideal for aquatic environment and fish development (Das Gupta et al., 2016).

The resuls describe above indictes that the physicochemical parameters studies are within the acceptable limits (Anita Bhatnagar and Pooja Devi, 2013) and the water quality of this beel is good enough to support rich high species diversity and suitable for fish culture.

\section{Fish Diversity}

A total of 37 species of fishes belonging to 9 orders, 22 families and 27 genera were obtained from the Rajar beel wetland. 
Table.1 Correlation matrix among the physicochemical parameters and Shannon-Wiener diversity Index of Rajar Beel wetland during March 2019 to February 2020.

\begin{tabular}{|c|c|c|c|c|c|c|c|c|c|c|}
\hline & $\mathbf{W} \mathbf{T}$ & pH & TUR & DO & $\mathrm{CO}_{2}$ & TH & TA & $\mathrm{NO}_{3}$ & $\mathrm{PO}_{4}^{-}$ & SW I \\
\hline $\mathrm{W} T\left({ }^{0} \mathrm{C}\right)$ & 1.000 & & & & & & & & & \\
\hline Ph & -0.986 & 1.000 & & & & & & & & \\
\hline TUR (cm) & 0.298 & -0.132 & 1.000 & & & & & & & \\
\hline DO (mg/l) & -0.894 & 0.957 & 0.161 & 1.000 & & & & & & \\
\hline $\mathrm{CO}_{2}(\mathrm{mg} / \mathrm{l})$ & 0.790 & -0.882 & -0.350 & -0.981 & 1.000 & & & & & \\
\hline TH (mg/l) & -0.763 & 0.643 & -0.844 & 0.393 & -0.207 & 1.000 & & & & \\
\hline TA(mg/l) & -0.959 & 0.993 & -0.016 & 0.984 & -0.931 & 0.550 & 1.000 & & & \\
\hline $\mathrm{NO}_{3}(\mathrm{mg} / \mathrm{l})$ & -0.713 & 0.821 & 0.457 & 0.951 & -0.993 & 0.091 & 0.882 & 1.000 & & \\
\hline $\mathrm{PO}_{4}^{-}(\mathrm{mg} / \mathrm{l})$ & -0.172 & 0.337 & 0.889 & 0.595 & -0.740 & -0.505 & 0.444 & 0.814 & 1.000 & \\
\hline SW I & -0.754 & 0.854 & 0.403 & 0.968 & -0.998 & 0.151 & 0.909 & 0.998 & 0.777 & 1.000 \\
\hline
\end{tabular}

Table.2 Species diversity indices in three different seasons

\begin{tabular}{|c|c|c|c|}
\hline & Shannon-Wiener Index & Evenness Index & Index of Dominance \\
\hline Pre-Monsoon & 2.899 & 0.803 & 0.090 \\
\hline Monsoon & 3.023 & 0.837 & 0.075 \\
\hline Post-Monsoon & 3.087 & 0.855 & 0.067 \\
\hline
\end{tabular}

Fig.1 Map (source: Google Map) of the study area with three sites pointed as Site I = Sadarhat Ghat, Site II = Taltala Ghat, Site III = Parthpur Ghat

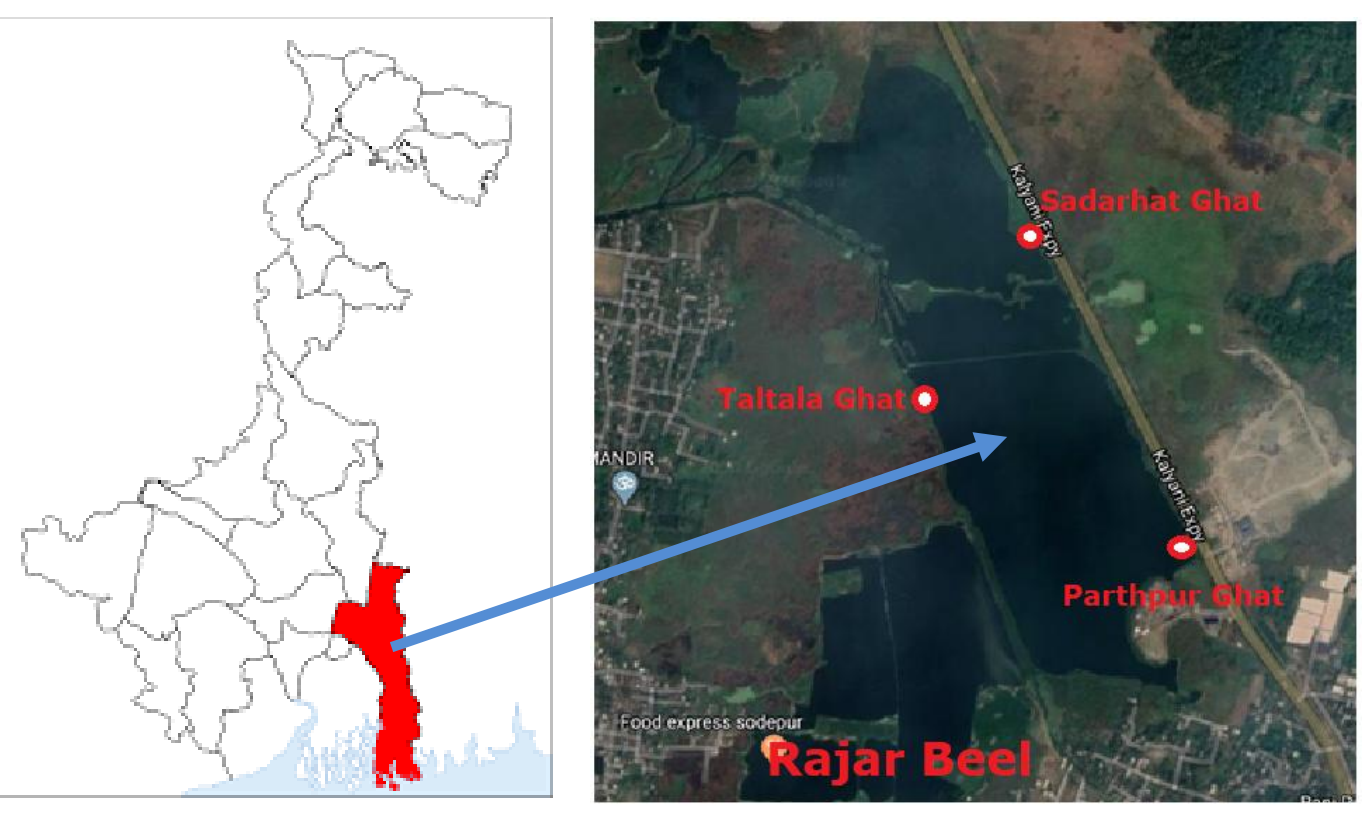


Fig.2 Seasonal variation in water quality parameters (mean values of 12 findings per quarter)
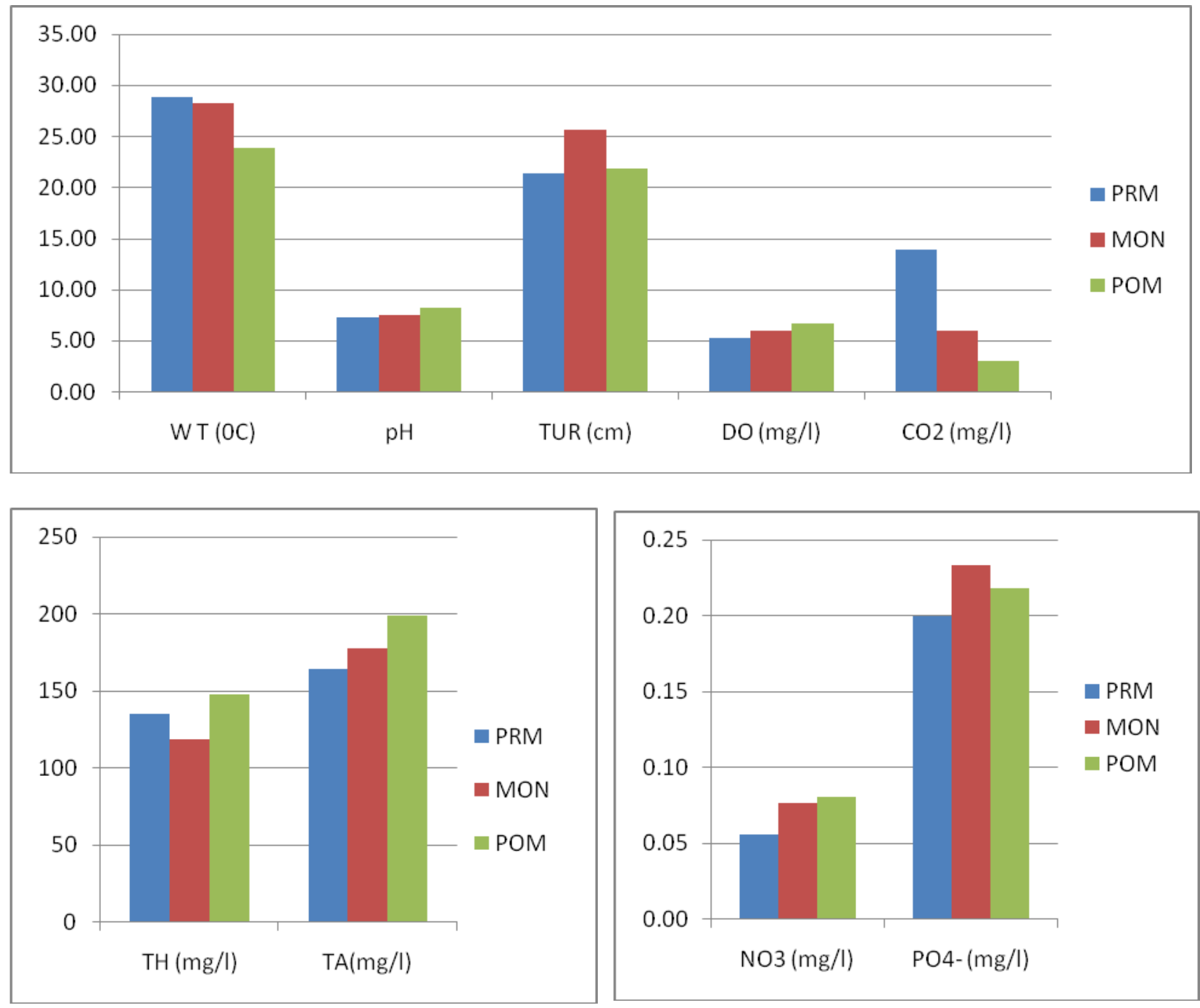
Fig.3 Heat map of Pearson correlation matrix between different physicochemical parameters and Shannon-Wiener diversity Index of Rajar beel from March 2019 to February 2020.

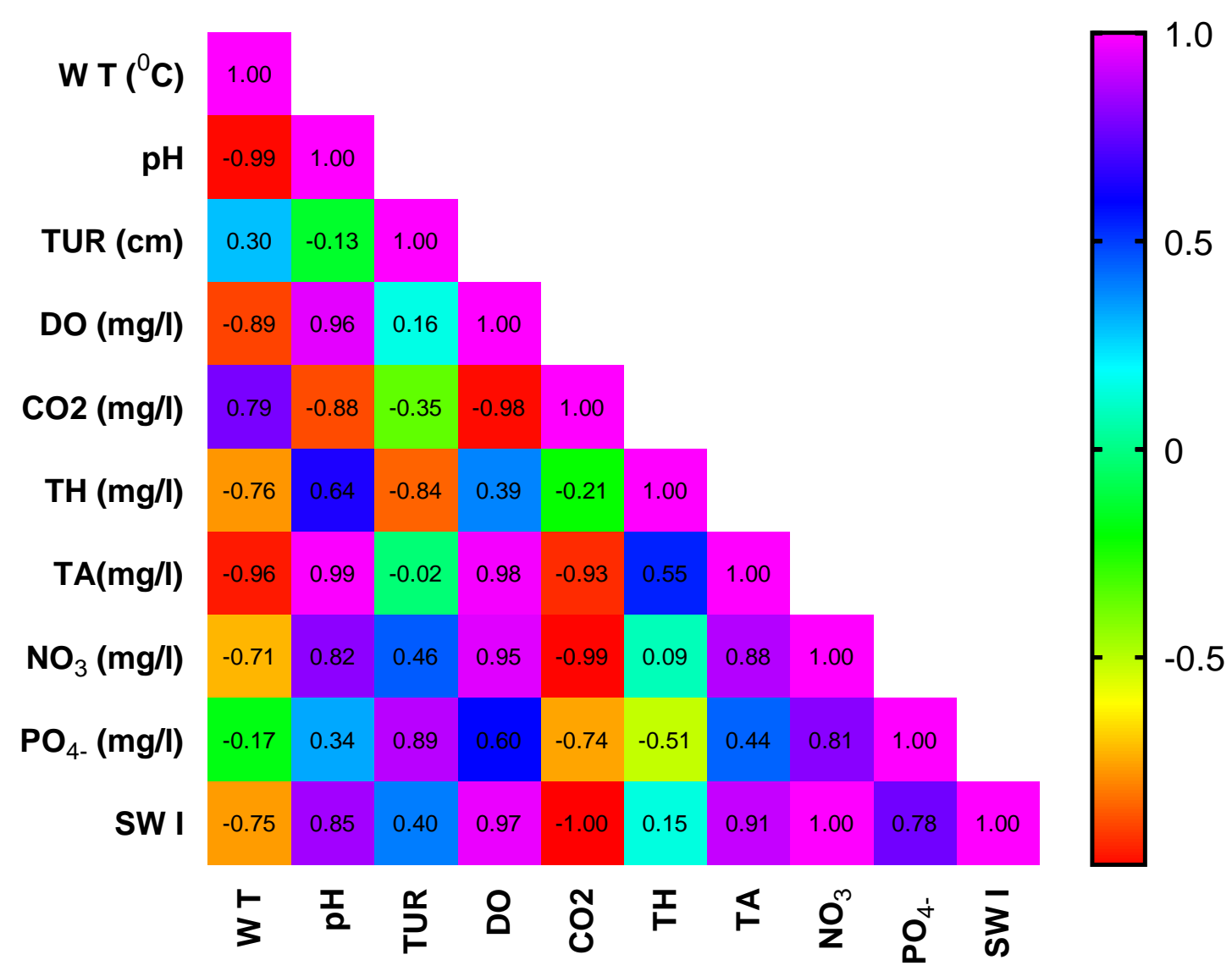

Fig.4 Relative abundance (RA) of various Fish order during March 2019 to February 2020

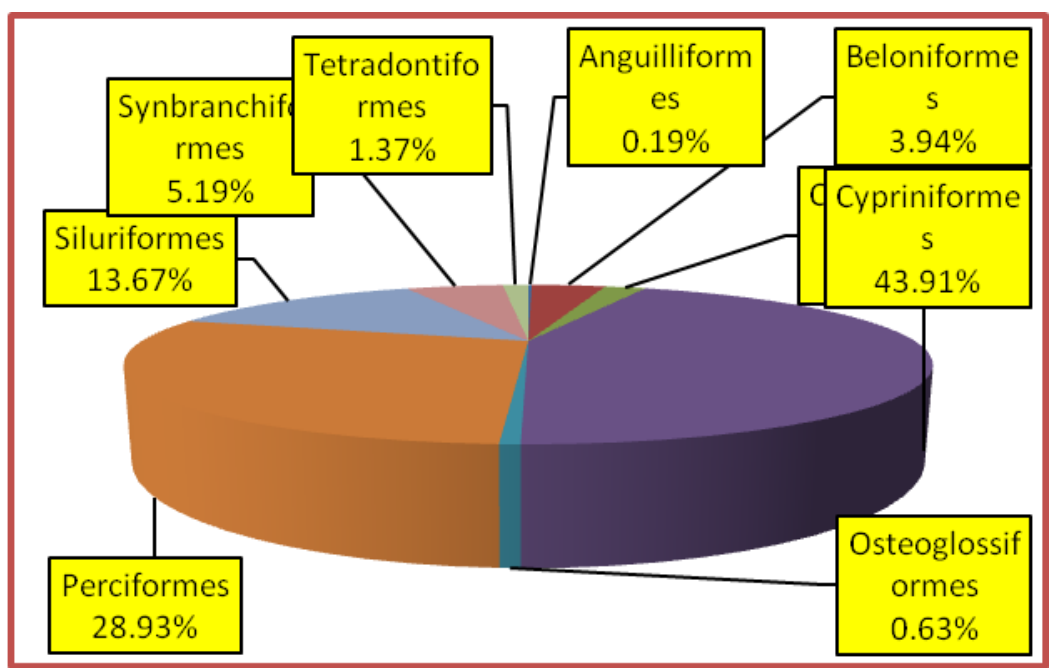


Out of those fishes, Cypriniformes was the most dominating order having 7 species with $43.91 \%$ catch composition, followed by Perciformes with 15 species and $28.93 \%$ catch composition, Siluriformes with 7 species and $13.67 \%$ catch composition, Synbrachiformes with 3 species and $5.19 \%$ catch composition and Beloniformes, Clupeiformes, Tetradontiformes, Osteoglossiformes and Anguilliformes was with one species and 3.94, $2.19, \quad 1.37, \quad 0.63$ and 0.19 percentage respectively catch composition (Figure 4).

Shannon diversity index $(\bar{H})$ was obtained highest (3.087) in Post-Monsoon and lowest (2.899) in pre-monsoon. Similarly, the species evenness was found highest in post-monsoon (0.855) and lowest in pre-monsoon (0.803). Both Shannon-Wiener diversity index $(\bar{H})$ and Evenness index highest during post-monsoon, while the index of dominance lowest during post-monsoon(0.067) and similarly it was observed that Index of Dominance highest during pre-monsoon(0.090) but Evenness index and Shannon-Wiener diversity index $(\bar{H})$ highest at that time (Table 2). The Shannonwiener index shows a negative correlation with water temperature and $\mathrm{CO}_{2}$ while positive relation with $\mathrm{pH}, \mathrm{DO}$ and phosphate. Natural as well as anthropogenic activities directly impact the relative abundance of species until it becomes an endangered species(Roy et al., 2013). Shannon-Wiener diversity index in the freshwater habitat and suggested a healthy environment with little alterations (Jewel et al., 2018). ShannonWiener diversity index $(\bar{H})$ of Rajar beel found matches with the findings of Iqbal et al.,(2015) (the range 2.90-3.12) in a freshwater wetland.

From the present study it is concluded that water quality of Rajar Beel is satisfactory for pisiculture. This beel has abundance fish diversity but the fish composition alter slightly with seasonal fluctuation. It is also observed that the seasonal variation has great impact on the physic chemical characteristic of water. The health status and fish diversity is found best during post monsoon period. The current state of this beel is considered as productive and healthy and appropriate for the fishery activities.

\section{Appendix}

$\mathrm{WT}=$ Water Temperature, TUR $=$ Turbidity, $\mathrm{DO}=$ Dissolve Oxygen, $\mathrm{CO}_{2}=$ Carbon Di Oxide, $\mathrm{BOD}=$ Biochemical Oxygen Demand, $\mathrm{TH}=$ Total Hardness, TA = Total Alkalinity, $\mathrm{PO}_{4}{ }^{-}=$Phosphate, $\mathrm{NO}_{3}=$ Nitrate, SWI = Shannon Wiener Index, PRM = Pre-Monsoon, MON = Monsoon, POM = Post-Monsoon, PCA = Principal Component Analysis, WHO $=$ World Health Organization, BIS = Indian Standards Bureau, CPCB = Central Pollution Control Board.

\section{Acknowledgement}

Authors acknowledge the facilities of research provided by Dr Soumendranath Chatterjee, Department of Zoology, The University of Burdwan. Authors are thankful to the fisherman associated with Rajar beel wetland for their needful help.

\section{References}

Abu Sayed Jewel, Md. Ayenuddin Haque, Reshma Khatun and Md. Shahinur Rahman (2018). A Comparative Study of Fish Assemblage and Diversity Indices in two Different Aquatic Habitats in Bangladesh: Lakhandaha Wetland and Atari River. Jordan Journal of Biological Sciences.,11(4): 427 - 434.

Abujam SKS, Dakua S, Bakalial B, Saikia AK, Biswas SP and Choudhury P (2011). Diversity of Plankton in Maijan, Upper Assam Beel. Asian Journal of Experimental Biological Sciences., 2(4): 562-568. 
Anita Bhatnagar and Pooja Devi (2013). Water quality guidelines for the management of pond fish culture. International Journal of Environmental Science., 3(6): 1980 - 2009.

Annual report 2004-2005 (2006). Department of Fisheries. Aquaculture, Aquatic Resources and Fishing Harbours, Government of West Bengal., 25-27.

APHA (2006). Standard methods for the examination of water and wastewater, 21st Edn. APHA, AWWA,WPCF, Washington, DC, USA.

Arya SK, Raikwar V, Dhaka M, Minakshi A (2011). Physico-chemical Analysis of Selected Surface Water Samples of Laxmi Tal (Pond) in Jhansi City, UP, Bundel Khand Region. Central India Journal of Experimental Sciences., 2(8): 01-06.

Barnes, B. V., Zak, D. R., Denton, S., Spurr, S. (1998). Forest ecology, John Wiley and Sons, INC., : 773.

Basavaraja, D., J. Narayana, B. R. Kiran, and E. T. Puttaiah (2014). Fish diversity and abundance in relation to water quality of Anjanapura Reservoir, Karnataka, India. International Journal of Current Microbiology and Applied Sciences., 3(3) : 747-757.

Bera, Amalesh \& Bhattacharya, Manojit \& Patra, Bidhan \& Sar, Utpal. (2014). Ichthyofaunal Diversity and Water Quality in the Kangsabati Reservoir, West Bengal, India. Advances in Zoology., 2014 : 1-8.

Bhatnagar and G. Singh (2010). Culture fisheries in village ponds - a multi location study in Haryana, India. Agriculture and Biology Journal of North America., 1(5): 961-968.

Bhaumik, U., B. C. Jha, K. Mitra, and G. K. Vinci (2003). Fish yield optimization in beels: Some case studies from West Bengal. Bulletin of Central Inland Fisheries Research Institute, Barrackpore., 125 : 4354.

Central Pollution Control Board, 2010; Standard water quality parameter guidelines.

Chapin FS 3rd, Zavaleta ES, Eviner VT (2000). Consequences of changing biodiversity. Nature., 405(6783): 234-242.
Das Gupta, Anirban \& Sarkar, Subhasis \& Singh, Jay Prakash \& Saha, Tapan \& Sil, Alok (2016). Nitrogen dynamics of the aquatic system is an important driving force for efficient sewage purification in single pond natural treatment wetlands at East Kolkata Wetland. Chemosphere., 164 : 576 $-584$.

Das SK, Chand BK (2003). Limnology and biodiversity of Ichthyofauna in a pond of Southern Orissa, India. Journal of Ecotoxicology and Environmental Monitoring., 13(2): 97-102.

Debnath, S and A K Panigrahi (2013). Studies on some limnological parameters of a floodplain wetland of West Bengal. Avifaunal diversity, Biospectra., 8(1) : 5156.

Golam Ziauddin, S. K. Chakraborty, A. K. Jaiswar and Utpal Bhaumik (2013). Seasonal Variation of Physicochemical Parameters of Selected Floodplain Wetlands of West Bengal. J Chem Bio Phy Sci., 3(4) : 2731-2743.

Hassan MA, Bhandhopadhyay MK, Jha BC, Sharma AP, Biswas BK (2011). Plankton and fish productivity pattern in two environmentally different oxbow lakes in West Bengal. Journal of Inland Fisheries Sciences., 43(1): 70-76.

Iqbal MM, Kanon MH, Hossain MA, Hossain A, Nasreen S, Islam MJ and Rahman MA (2015). Diversity of indigenous fish species in Konoskhaihaor, Northeast Bangladesh. Punjab Uni J Zool., 30(2): 73-79.

Jain SM, Sharma M, Thakur R (1996). Seasonal variation in physicochemical parameters of Halali reservoir of Vidisha Dist. Indian Journal of Ecobiology., 8(3): 181-188.

Jawale AK, Patil SA (2009). Physico-chemical characteristics and Phytoplanktons abundance of Mangrul dam, Dist-Jalgaon, Maharashtra. Journal of Aquatic Biology., 24(1): 7-12.

Karen De Roy, Massimo Marzorati, Andrea Negroni, Olivier Thas, Annalisa Balloi, Fabio Fava, Willy Verstraete, Daniele Daffonchio \& Nico Boon (2013). Environmental conditions and community 
evenness determine the outcome of biological invasion. Nature Communications., $4: 1383$.

Kaur VB, Bath KS, Mandar G (1996). Abiotic and biotic components of a freshwater pond of Patiala (Punjab). Journal of Pollution Research., 15(3): 253-256.

Keshre, V. and L. K. Mudgal (2010). Study on fish diversity \& fish production of Moghat Reservoir, Khandwa (M.P.). Journal of Environmental Conservation., 11(3) : 117120.

Kumar, N. (2012). Study on ichthyofaunal biodiversity of Turkaulia Lake, EastChamparan, Bihar, India. International Research Journal of Environmental Sciences., 1(2) : 21-24.

Madhuri P, Gurav M (2008). Seasonal variations of zooplankton in Nirmalya (religious refuges) enclosure of Kalawa Lake, Thane, Maharashtra. Journal of Aquatic Biology.. 23(1): 22-25.

Mamta Joshi, Umerfaruq Qureshimatva and Hitesh A. Solanki (2019). PhysicoChemical Parameters of Water in Wadhwana Wetland, Vadodara, Gujarat. Vidya., 1 : 98-107.

Mishra S, Singh LA, Tiwary D (2014). Studied of physicochemical status of the ponds at Varanasi Holy City under Anthropogenic influences. International Journal of Environment Research and Development., 4: 261-268.

Mondal, D. K. and A. Kaviraj (2008). Ecotoxicological effects of jute retting on the survival of two freshwater fish and two invertebrates. Ecotoxicology., 17: 207-211.
Mondal, D. K. and A. Kaviraj (2010). Water Quality Parameters and Fish Biodiversity Indices as Measures of Ecological Degradation: A Case Study in Two Floodplain Lakes of India. $\mathbf{J}$ Water Resource and Protection., 2 : 85-92.

Naik Kumar \& Kumar Jitendra \& Hulkoti Srinivas (2013). Studies on Ichthyofaunal Diversity of Karanja Reservoir, Karnataka, India. Int Res J Environ Sci., 2 : 2319-1414.

Nasim Ahmad Ansari (2017). Seasonal variations in physicochemical characteristics of water samples of Surajpur wetland, national capital region, India. Int J Curr Microbiol App Sci., 6(2) : 971-987.

Ramsar Convention Burea (2012). Guideline for the future development of the list of wetland.

Sarkar, L. and S. Benerjee (2000). Ichthyofauna of Damodar river system. Proceedings of the Zoological Society (Calcutta)., 53(1) : 41-54.

Sharma RC, Singh N and Chauhan A (2016). The influence of physicochemical parameters on phytoplankton distribution in a headwater stream of Garhwal Himalayas: A case study. Egyptian Journal of Aquatic Research., 42: 11-21.

Shinde SE, Pathan S, Raut KS, Sonawane DL (2011). Studies on the Physico-chemical parameters and correlation coefficient of Harsool-Savangi Dam, District Aurangabad, India. Middle-East Journal of Scientific Research., 8(3): 544-554.

Singh, M. (2011). Study of plankton abundance in fresh water fish pond at Malawan, Etah (UP). Indian Journal of Biological Studies and Research., 1(1) : 39-44.

\section{How to cite this article:}

Triparna Chakraborty and Nimai Chandra Saha. 2021. Study on Seasonal Fluctuation of Physicochemical Properties of Water and Fish Diversity Towards Future Management of a Natural Water Bodies Rajar Beel Wetland, North 24 Parganas, West Bengal, India. Int.J.Curr.Microbiol.App.Sci. 10(04): 671-680. doi: https://doi.org/10.20546/ijcmas.2021.1004.067 